\title{
Microwave dielectric properties and vibrational spectroscopic analysis of $\mathrm{MgTe}_{2} \mathrm{O}_{5}$ ceramics
}

\author{
G. Subodh \\ Materials and Minerals Division, National Institute for Interdisciplinary Science and Technology \\ (NIST), Trivandrum-695 019, India \\ R. Ratheesh \\ Microwave Materials Division, Centre for Materials in Electronics (C-MET), Thrissur-680 771, India \\ M.V. Jacob \\ School of Engineering, James Cook University, Townsville, QLD 4811, Australia \\ M.T. Sebastian ${ }^{\text {a) }}$ \\ Materials and Minerals Division, National Institute for Interdisciplinary Science and Technology \\ (NIST), Trivandrum-695 019, India
}

(Received 10 August 2007; accepted 12 December 2007)

\begin{abstract}
$\mathrm{MgTe}_{2} \mathrm{O}_{5}$ ceramics were prepared by solid-state route. These materials were sintered in the temperature range of $640-720^{\circ} \mathrm{C}$. The structure and microstructure of the compound was investigated using x-ray diffraction (XRD), Fourier transform infrared (FTIR), Raman spectroscopy, and scanning electron microscopy (SEM) techniques. The dielectric properties of the ceramics were studied in the frequency range 4-6 GHz. The $\mathrm{MgTe}_{2} \mathrm{O}_{5}$ ceramics have a dielectric constant $\left(\epsilon_{\mathrm{r}}\right)$ of 10.5 , quality factors $\left(Q_{\mathrm{u}} \times f\right)$ of 61000 at $5.3 \mathrm{GHz}$, and temperature coefficient of resonant frequency $\left(\tau_{\mathrm{f}}\right)$ of -45 $\mathrm{ppm} /{ }^{\circ} \mathrm{C}$ at the optimized sintering temperature of $700{ }^{\circ} \mathrm{C}$. The microwave dielectric properties of these materials at cryogenic temperatures were also investigated.
\end{abstract}

\section{INTRODUCTION}

Extensive research has been carried on the microwave ceramics for their use in telecommunication systems. ${ }^{1-4}$ Recently, low-temperature cofired ceramic (LTCC) technology has become critically important in the development of electronic devices for wireless communication. ${ }^{1-4}$ The use of LTCC technology can also facilitate integration of passive components and has the ability to use highly conductive and inexpensive metallization, quick prototyping, compact structures, and integration. ${ }^{3}$ For the cofiring process, the melting point of electrode determines the sintering temperature of the LTCC module. However, reducing the sintering temperature without affecting properties is a challenging problem in LTCC material research., ${ }^{5,6}$ The sintering temperature of the ceramics can be lowered by the addition of low melting glasses, chemical processing, and small particle size of starting materials. ${ }^{7}$ However, chemical synthesis complicates the fabrication method and also increases the cost of production. Addition of glasses leads to poor dielectric properties and also increases the chance of chemical reaction with metal electrodes. ${ }^{8,9}$ The soldering of LTCC tapes can cause formation of cracks due to the difference

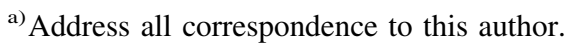

e-mail: mailadils@yahoo.com

DOI: $10.1557 / J M R .2008 .0212$
}

in thermal expansion coefficients of the glass and ceramics. ${ }^{8,9}$ Thus, glass-free materials with good microwave properties are strongly advised for LTCC applications.

Even though a large number of low-temperature sinterable microwave dielectric materials are reported, the stringent requirements of the LTCC technology has forced researchers to find more suitable candidates. Recently, a number of tellurium-based low-temperature sinterable dielectric resonator materials have been reported. ${ }^{10-14}$ Kwon et al. ${ }^{10}$ reported the microwave dielectric properties of $\mathrm{BaTe}_{4} \mathrm{O}_{9}$ ceramics. However, this material has relatively high negative $\tau_{\mathrm{f}}$ of $-90 \mathrm{ppm} /{ }^{\circ} \mathrm{C}$. A number of new materials in the $\mathrm{Bi}_{2} \mathrm{O}_{3}-\mathrm{TeO}_{2}$ system were also investigated by Udovic et al. ${ }^{13}$ However, the dielectric constant of these materials prevents their application as substrates. Hence, the search for an ideal glass-free LTCC material with good properties continues. In the present paper, we report the microwave dielectric properties of the $\mathrm{MgTe}_{2} \mathrm{O}_{5}$ ceramics for the first time. The infrared (IR) and Raman spectra of these materials were also studied to correlate the structure with properties. The recent advances in the high-temperature superconductors allowed significant reduction of noise in microwave filters and oscillators. The manufacturing of such low-loss devices requires dielectric material with extremely good properties. ${ }^{15}$ Thus, the microwave dielectric properties of $\mathrm{MgTe}_{2} \mathrm{O}_{5}$ ceramics were also investigated at cryogenic temperatures. 


\section{EXPERIMENTAL}

$\mathrm{MgTe}_{2} \mathrm{O}_{5}$ ceramics were prepared by the solid-state ceramic route. High-purity $\left(\mathrm{MgCO}_{3}\right)_{4} \mathrm{Mg}(\mathrm{OH})_{2} \cdot 5 \mathrm{H}_{2} \mathrm{O}$ and $\mathrm{TeO}_{2}(99+\%$, Aldrich Chemical Company, St. Louis, MO) were used as the starting materials. Stoichiometric amounts of powder mixtures were ball-milled in distilled water medium using yttria-stabilized zirconia balls in a plastic container for $24 \mathrm{~h}$. The slurry was dried, then ground well, and calcined at $600{ }^{\circ} \mathrm{C} / 8 \mathrm{~h}$ with intermediate grinding. The calcined material was ground into fine powder and divided into different batches for optimizing sintering temperature. It was then mixed with $4 \mathrm{wt} \%$ PVA (molecular weight 22000, BDH Lab Suppliers, Poole, UK) and again dried and ground well. Cylindrical pucks of about 10-11 $\mathrm{mm}$ height and about $20 \mathrm{~mm}$ diameter were made by applying a pressure of $150 \mathrm{MPa}$. These compacts were then fired at $500{ }^{\circ} \mathrm{C}$ for $2 \mathrm{~h}$ to expel the binder before sintering at temperatures ranging from 640 to $720{ }^{\circ} \mathrm{C}$ for $4 \mathrm{~h}$. The bulk densities of the sintered samples were measured using Archimedes's method.

The crystal structure and phase purity of the powdered samples were studied by x-ray diffraction (XRD) technique using $\mathrm{Cu} \mathrm{K}_{\alpha}$ radiation (Philips x-ray diffractometer; Eindhoven, The Netherlands). The sintered samples were thermally etched for $20 \mathrm{~min}$ at a temperature of about $25^{\circ} \mathrm{C}$ below the sintering temperature, and the surface morphology and energy dispersive $\mathrm{x}$-ray (EDX) spectra were recorded using a scanning electron microscope (SEM; JEOL-JSM 5600 LV, Tokyo, Japan). $\mathrm{MgTe}_{2} \mathrm{O}_{5}$ ceramics sintered at $700{ }^{\circ} \mathrm{C}$ were used for the spectroscopic studies. The powdered ceramics were mixed with $\mathrm{KBr}$, and the IR spectrum was taken from Shimadzu IR Prestige 21 (Kyoto, Japan). A powdered sample of $\mathrm{MgTe}_{2} \mathrm{O}_{5}$ ceramics was used to take Raman spectra (Bruker, RFS 1001s; Billerica, MA). A Nd-yttrium aluminum garnet (YAG) laser with a wavelength of $1064 \mathrm{~nm}$ and a Ge target was used for the measurement.

The microwave dielectric properties were measured by a Vector Network Analyzer (8753 ET, Agilent Technologies, Palo Alto, CA), which can be used at frequencies from $300 \mathrm{KHz}$ to $6 \mathrm{GHz}$. The dielectric constant and unloaded quality factor of the samples were measured by Hakki and Coleman ${ }^{16}$ and the cavity method, ${ }^{17}$ respectively, in the frequency range 4-6 GHz. The specimen was placed on a low-loss quartz spacer inside a copper cavity whose inner side was silver plated. The use of low-loss single-crystal quartz spacer reduces the effect of losses due to the surface resistivity of the cavity. The diameter of the cavity was about 4 times larger than that of the sample for better isolation of the excited $\mathrm{TE}_{01 \delta}$ mode. The $\tau_{\mathrm{f}}$ was measured by noting the variations of $\mathrm{TE}_{01 \delta}$ mode frequency with temperature in the range of 25 to $75^{\circ} \mathrm{C}$.

The measurement system implemented for microwave characterization of the samples at cryogenic temperatures consisted of Network Analyser (HP 8722C, Agilent Technologies), closed-cycle refrigerator (APD DE-204), temperature controller (LTC-10), vacuum dewar, and a PC. The S-parameters $\left(S_{21}, S_{11}\right.$, and $\left.S_{22}\right)$ around various resonances were measured employing the Simplified Transmission Mode Q-Factor (TMQF) technique, ${ }^{18}$ which accounts for noise, delay due to uncalibrated transmission lines and its frequency dependence and cross-talk in measurement data, was used for data processing. Hence, the accurate values of $Q_{\mathrm{L}}$ and the coupling coefficients $\beta_{1}$ and $\beta_{2}$ were provided. ${ }^{18}$ The unloaded $Q_{0}$-factor was subsequently calculated using the exact equation

$$
Q_{0}=Q_{\mathrm{L}}\left(1+\beta_{1}+\beta_{2}\right)
$$

The shrinkage of the $\mathrm{MgTe}_{2} \mathrm{O}_{5}$ ceramics was measured using a thermomechanical analyzer (TMA-60H Shimadzu, Kyoto, Japan) in the temperature range $30-700{ }^{\circ} \mathrm{C}$.

\section{RESULTS AND DISCUSSION}

Figure 1 shows the XRD patterns of calcined and sintered $\mathrm{MgTe}_{2} \mathrm{O}_{5}$ ceramics at 600 and $700{ }^{\circ} \mathrm{C}$. The crystal structure of $\mathrm{MgTe}_{2} \mathrm{O}_{5}$ has previously been investigated. ${ }^{19,20} \mathrm{MgTe}_{2} \mathrm{O}_{5}$ has orthorhombic symmetry with space group Pbcn. The material contains $\mathrm{Te}_{2} \mathrm{O}_{5}$ groups in which Te (IV) is surrounded by three oxygen atoms in pyramidal arrangements, and one oxygen is common to both Te atoms. ${ }^{19}$ There has been no significant difference in the XRD pattern of the calcined and sintered specimen, indicating no change in crystal structure with respect to sintering temperature. The XRD pattern is indexed based on the report of Weil. ${ }^{20}$ The obtained lattice parameters, $a=7.265(2) \AA, b=10.666(4) \AA$, and $c=$ 5.997(9) $\AA$ are in good agreement with an earlier

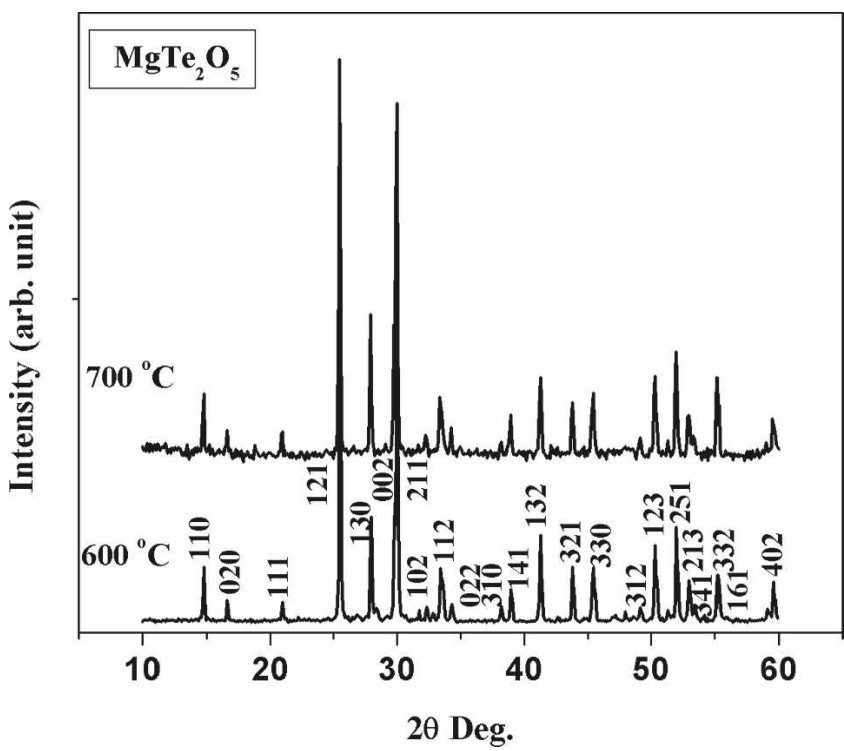

FIG. 1. XRD profile of $\mathrm{MgTe}_{2} \mathrm{O}_{5}$ calcined and sintered at 600 and $700{ }^{\circ} \mathrm{C}$, respectively. 
report. ${ }^{20}$ Figure 2 (a) shows the SEM image of thermally etched $\mathrm{MgTe}_{2} \mathrm{O}_{5}$ ceramics sintered at $700{ }^{\circ} \mathrm{C}$. It can be noted that the average grain size of the ceramics varies from 1 to $3 \mu \mathrm{m}$. However, the presence of a very small amount of glasslike phases can also be seen from the microstructure. To identify the glassy phase, EDX analysis of the specimen was performed. The EDX analysis shown in the Fig. 2(b) reveals the presence of $\mathrm{Mg}$, Te, and $\mathrm{O}$ in nearly the same atomic percentage of $\mathrm{MgTe}_{2} \mathrm{O}_{5}$ ceramics. Thus it can be concluded that $\mathrm{MgTe}_{2} \mathrm{O}_{5}$ ceramics started melting at $700{ }^{\circ} \mathrm{C}$.

Figure 3 shows the shrinkage behavior of $\mathrm{MgTe}_{2} \mathrm{O}_{5}$ ceramics. The specimen exhibits a rapid increase in shrinkage above $600{ }^{\circ} \mathrm{C}$. It can be noted that about $6 \%$ shrinkage is observed for $\mathrm{MgTe}_{2} \mathrm{O}_{5}$ ceramics at the optimized sintering temperature.

Figure 4 shows the Raman spectrum of the $\mathrm{MgTe}_{2} \mathrm{O}_{5}$ ceramics sintered at $700{ }^{\circ} \mathrm{C}$. The Raman spectrum of $\mathrm{MgTe}_{2} \mathrm{O}_{5}$ in the present study resembles that reported

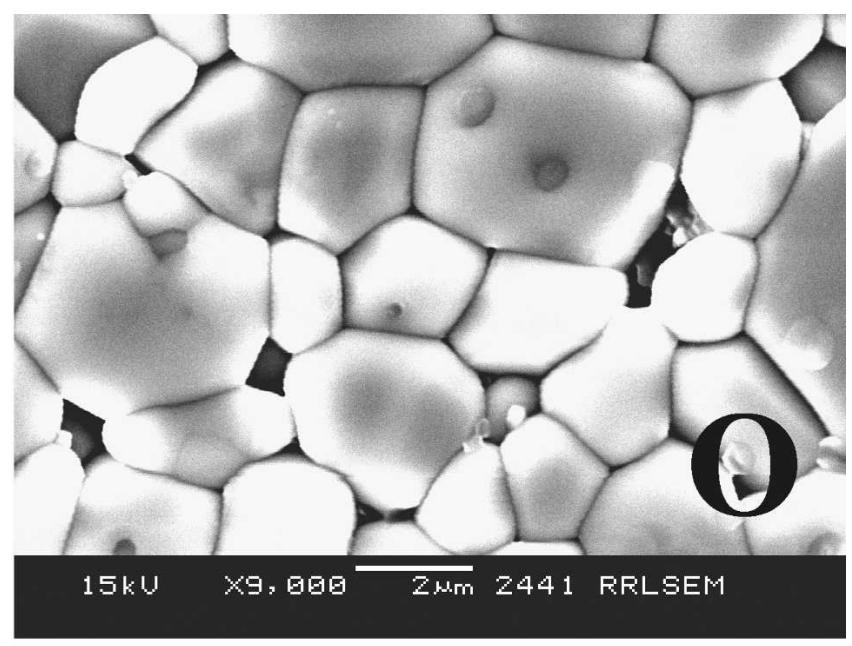

(a)

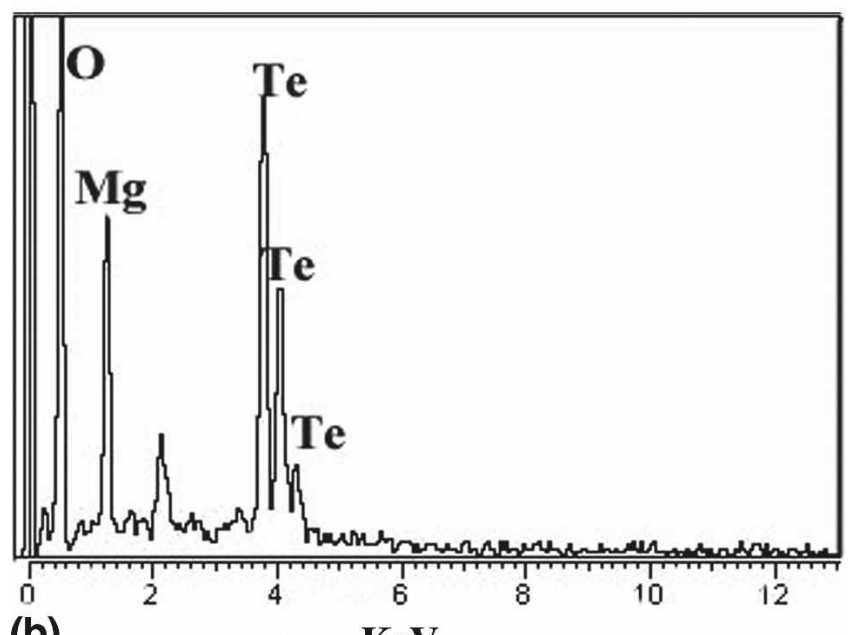

(b)

$\mathrm{KeV}$

FIG. 2. SEM picture of $\mathrm{MgTe}_{2} \mathrm{O}_{5}$ ceramics sintered at $700{ }^{\circ} \mathrm{C}$ and EDX spectra of the marked phase in the microstructure.

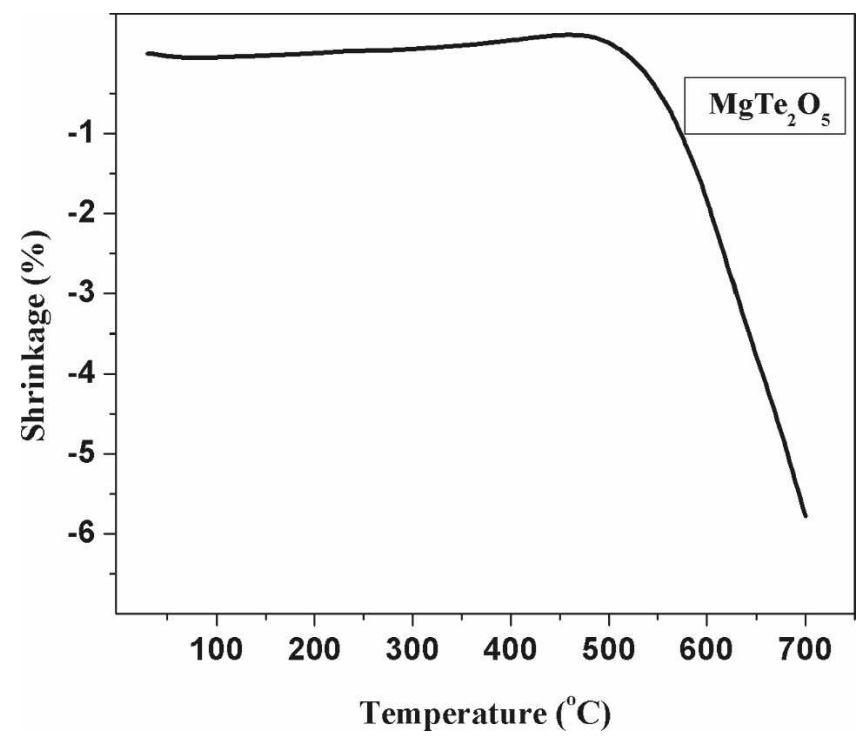

FIG. 3. Shrinkage behavior of $\mathrm{MgTe}_{2} \mathrm{O}_{5}$ ceramics.

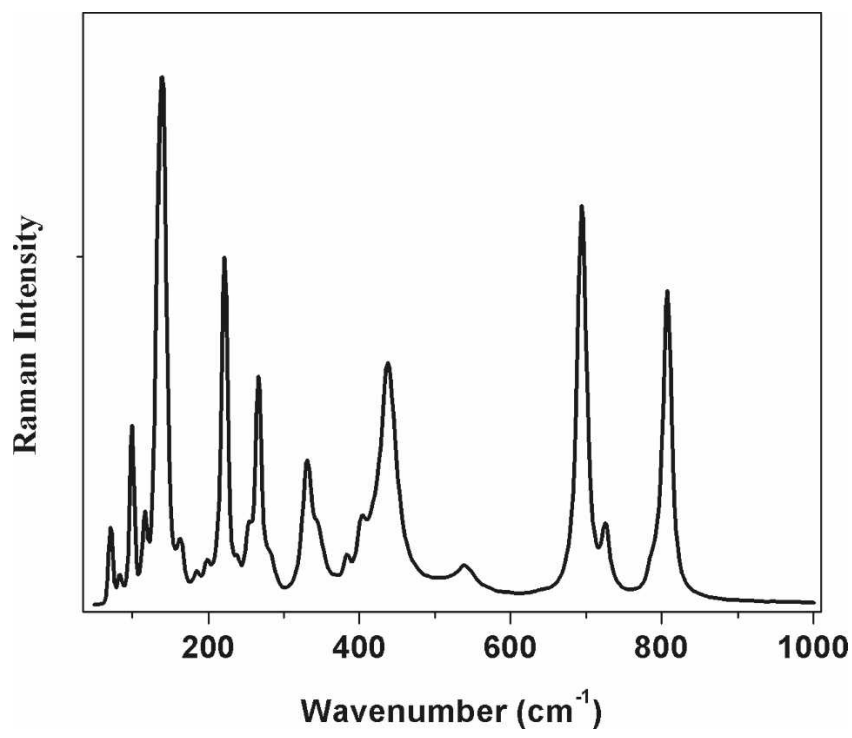

FIG. 4. Raman spectrum of $\mathrm{MgTe}_{2} \mathrm{O}_{5}$ ceramics sintered at $700{ }^{\circ} \mathrm{C}$.

earlier by Baran, ${ }^{21}$ except in the lattice mode region. The factor group analysis carried out in this work predicts 60 internal modes of vibrations for the $\mathrm{Te}_{2} \mathrm{O}_{5}$ groups:

$$
\begin{aligned}
\lceil\text { int }= & 8 \mathrm{~A}_{\mathrm{g}}+7 \mathrm{~B}_{1 \mathrm{~g}}+8 \mathrm{~B}_{2 \mathrm{~g}}+7 \mathrm{~B}_{3 \mathrm{~g}}+8 \mathrm{~A}_{\mathrm{u}}+7 \mathrm{~B}_{1 \mathrm{u}}+8 \mathrm{~B}_{2 \mathrm{u}} \\
& +7 \mathrm{~B}_{3 \mathrm{u}} .
\end{aligned}
$$

Out of these $A_{g}, B_{1 g}, B_{2 g}$, and $B_{3 g}$ are Raman active; $\mathrm{B}_{1 \mathrm{u}}, \mathrm{B}_{2 \mathrm{u}}$, and $\mathrm{B}_{3 \mathrm{u}}$ are IR active; and $\mathrm{A}_{\mathrm{u}}$ mode is inactive in both Raman and IR. The Te atom in $\mathrm{MgTe}_{2} \mathrm{O}_{5}$ is coordinated by three $\mathrm{O}$ atoms with short Te distances $<2 \AA$ and augmented by a fourth $\mathrm{O}$ atom at a distance of $2.4048 \AA$, resulting in a distorted $[3+1]$ polyhedron. ${ }^{20} \mathrm{The} \mathrm{TeO}_{3+1}$ groups are defined as trigonal bipyramids, for which one of the $\mathrm{Te}-\mathrm{O}$ distances corresponds to an intermediate bond $(2.405 \AA)$ according to Brown's classification. ${ }^{22}$ 
The three-dimensional structure is composed of zigzag chains of edge-sharing $\mathrm{MgO}_{6}$ octahedra and $\mathrm{TeO}_{3+1}$ units, with the later forming an extended sheet structure. The vibrational analysis of $\mathrm{MgTe}_{2} \mathrm{O}_{5}$ is reported by Baren $^{21}$ where in $\mathrm{Te}_{2} \mathrm{O}_{5}{ }^{2-}$ polyhedra are assigned on the basis of stretching and bending vibrations of $\mathrm{TeO}_{2}$ groups and $\mathrm{Te}-\mathrm{O}-\mathrm{Te}$ bridges. In the present study, the symmetric stretching vibrations of $\mathrm{TeO}_{2}$ groups in $\mathrm{Te}_{2} \mathrm{O}_{5}{ }^{2-}$ polyhedra are observed at $807 \mathrm{~cm}^{-1}$ as a strong band (Fig. 4). The very strong band observed at $789 \mathrm{~cm}^{-1}$ in the IR spectrum corresponds to $v_{\mathrm{s}} \mathrm{TeO}_{2}{ }^{23}$ (Fig. 5). The asymmetric stretching vibrations of $\mathrm{TeO}_{2}$ groups resulted two bands, a very strong one at $695 \mathrm{~cm}^{-1}$ and a small band at $723 \mathrm{~cm}^{-1}$ in the Raman spectrum, whereas a strong broad feature appearing in the $700-759 \mathrm{~cm}^{-1}$ range of IR spectrum is ascribed to $v_{\text {as }} \mathrm{TeO}_{2}$. The bending modes of $\mathrm{TeO}_{2}$ groups are also seen in both IR and Raman spectra of $\mathrm{MgTe}_{2} \mathrm{O}_{5}$ compound (Table I).

The presence of a medium broad band observed in the Raman spectrum of $\mathrm{MgTe}_{2} \mathrm{O}_{5}$ ceramics at $542 \mathrm{~cm}^{-1}$ is a characteristic feature of symmetric stretching vibrations of bridging $\mathrm{Te}-\mathrm{O}-\mathrm{Te}$ bonds. The corresponding mode in the IR spectrum appeared at $552 \mathrm{~cm}^{-1}$ as a medium intense band. The asymmetric stretching vibrations of $\mathrm{Te}-\mathrm{O}-\mathrm{Te}$ bridging mode gave rise to a strong band in the IR spectrum at $621 \mathrm{~cm}^{-1}$, whereas no Raman counterpart is observed for this mode. The appearance of a strong band corresponding to asymmetric stretching vibrations of $\mathrm{Te}-$ $\mathrm{O}-\mathrm{Te}$ in the IR spectrum can be attributed to the nonlinear nature of this bridging group $\left(120.91^{\circ}\right)$ as evidenced from the structural studies. ${ }^{19,20}$

The Raman bands observed in the $382-329 \mathrm{~cm}^{-1}$ are assigned to rocking modes, and those observed below $283 \mathrm{~cm}^{-1}$ are regarded as lattice mode region. An unambiguous assignment of these modes is not possible since this region consists of vibrations due to translational and

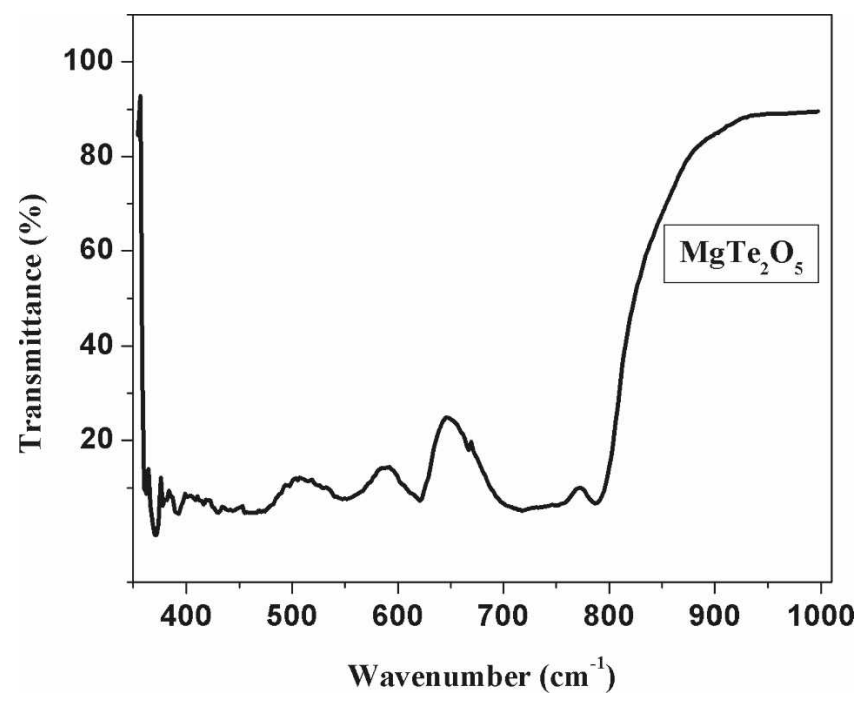

FIG. 5. IR spectrum of $\mathrm{MgTe}_{2} \mathrm{O}_{5}$ ceramics sintered at $700^{\circ} \mathrm{C}$.
TABLE I. Spectral data and band assignments of $\mathrm{MgTe}_{2} \mathrm{O}_{5}$ ceramics (wave number in $\left.\mathrm{cm}^{-1}\right)^{\mathrm{a}}$

\begin{tabular}{lll}
\hline \hline Raman & \multicolumn{1}{c}{ Infrared } & \multicolumn{1}{c}{ Assignments } \\
\hline $807 \mathrm{vs}$ & $789 \mathrm{vs}$ & $v_{\mathrm{s}}\left(\mathrm{TeO}_{2}\right)$ \\
$723 \mathrm{w}$ & 759 to $700 \mathrm{vsbr}$ & $\nu_{\text {as }}\left(\mathrm{TeO}_{2}\right)$ \\
$695 \mathrm{vvs}$ & & \\
$\quad \ldots$ & $621 \mathrm{~s}$ & $v_{\text {as }}(\mathrm{TeOTe})$ \\
$542 \mathrm{w}$ & $552 \mathrm{mbr}$ & $v_{\mathrm{s}}\left(\mathrm{TeOTe}^{2}\right)$ \\
$439 \mathrm{~s}$ & 470 to $426 \mathrm{wbr}$ & $\delta\left(\mathrm{TeO}_{2}\right)$ \\
$401 \mathrm{w}$ & & \\
$382 \mathrm{vw}$ & & \\
$347 \mathrm{sh}$ & & \\
$329 \mathrm{~m}$ & & \\
$282 \mathrm{sh}$ & & \\
$267 \mathrm{~s}$ & & \\
$250 \mathrm{wsh}$ & & \\
$220 \mathrm{~s}$ & & \\
$196 \mathrm{vw}$ & & \\
$182 \mathrm{vw}$ & & \\
$162 \mathrm{w}$ & & \\
$137 \mathrm{vvs}$ & & \\
$115 \mathrm{w}$ & & \\
$98 \mathrm{~m}$ & \\
$69 \mathrm{w}$ & & \\
\hline \hline
\end{tabular}

${ }^{\text {a) }}$, strong; vs, very strong; vvs, very very strong; m, medium; w, weak; sh, shoulder.

rotational of $\mathrm{Te}_{2} \mathrm{O}_{5}{ }^{2-}$ ions and metal oxygen stretching and bending modes. It is reported that the tellurium-based binary oxides exist as tellurites $\left(4^{+}\right)$and tellurates $\left(6^{+}\right)$in tellurium compounds. Although the tellurites are stable at room temperature, their oxidation to tellurates may happen in air, and the oxidation begins at $350-600{ }^{\circ} \mathrm{C}$ temperatures, depending on the characteristic of the tellurite composition. ${ }^{24}$ In the present study, although the samples are sintered at $700{ }^{\circ} \mathrm{C}$, the vibrational analysis did do show any presence of secondary phases in $\mathrm{MgTe}_{2} \mathrm{O}_{5}$ ceramics and the tellurium exist with $4+$ nominal charges.

Figure 6(a) shows the variation in density and $\epsilon_{\mathrm{r}}$ of $\mathrm{MgTe}_{2} \mathrm{O}_{5}$ ceramics with sintering temperature. As the sintering temperature increases, the density and dielectric constant reach maximum values of $4.5 \mathrm{~g} / \mathrm{cm}^{3}$ and 10.5 , respectively, at $700{ }^{\circ} \mathrm{C}$, and subsequent increase in temperature deteriorates the density and $\epsilon_{\mathrm{r}}$. Most of the tellurium-based compounds have a low melting point. A detailed analysis of the microstructure and EDX spectra reveals partial melting of the $\mathrm{MgTe}_{2} \mathrm{O}_{5}$ ceramics on sintering at $700{ }^{\circ} \mathrm{C}$ (see Fig. 2). Hence it can be concluded that the formation of glassy $\mathrm{MgTe}_{2} \mathrm{O}_{5}$ decreases the density and $\epsilon_{\mathrm{r}}$ of the ceramics on sintering above $700{ }^{\circ} \mathrm{C}$. Figure 6(b) shows the variation $Q_{\mathrm{u}} \times f$ and $\tau_{\mathrm{f}}$ with sintering temperature. A significant variation in $Q_{\mathrm{u}} \times f$ is observed for $\mathrm{MgTe}_{2} \mathrm{O}_{5}$ ceramics with sintering temperature. Also, irrespective of the low sintering temperature of the $\mathrm{MgTe}_{2} \mathrm{O}_{5}$ ceramics, it exhibits high quality factors. The variation of the quality factor with sintering temperature can be well correlated with bulk density of 

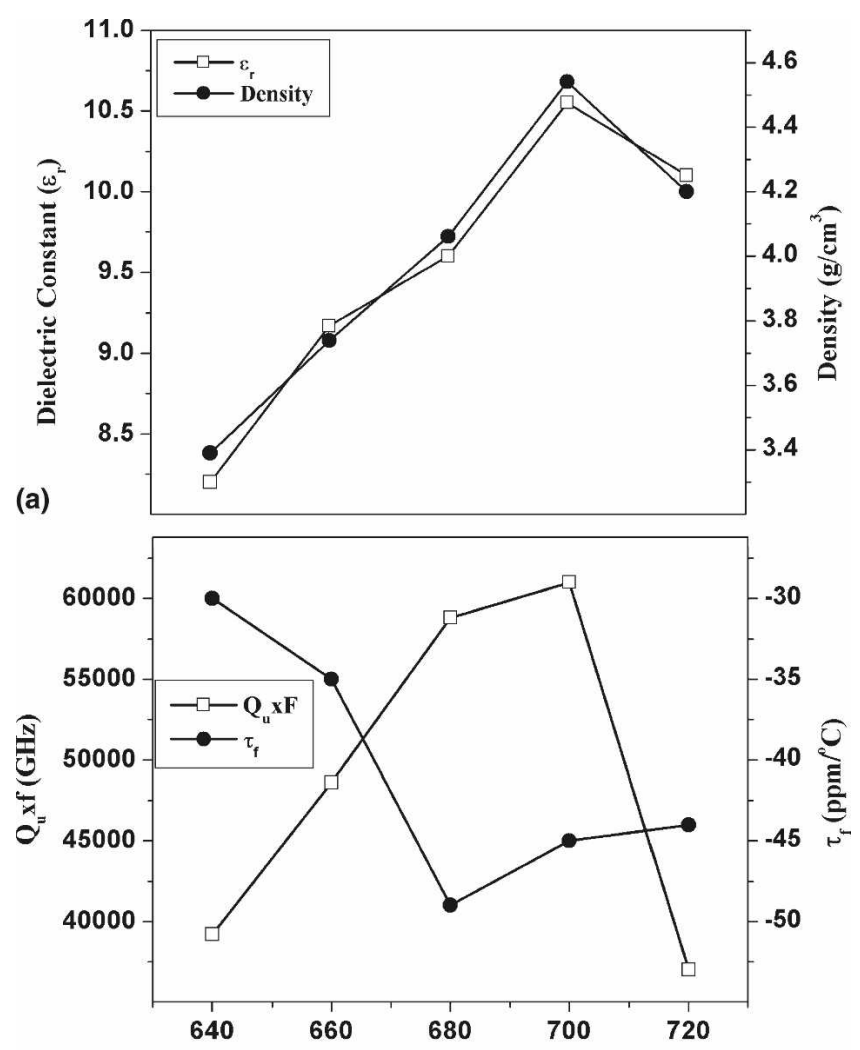

(b)

Sintering Temperature $\left({ }^{\circ} \mathrm{C}\right)$

FIG. 6. Density and microwave dielectric properties of $\mathrm{MgTe}_{2} \mathrm{O}_{5}$ ceramics with sintering temperature.

the specimen. The $\tau_{\mathrm{f}}$ of $\mathrm{MgTe}_{2} \mathrm{O}_{5}$ ceramics varies from -30 to $-46 \mathrm{ppm} /{ }^{\circ} \mathrm{C}$. The variation in $\tau_{\mathrm{f}}$ can be due to the change occurring in the temperature coefficient of dielectric constant with sintering temperature. The material has $\epsilon_{\mathrm{r}}$ of $10.5( \pm 0.5), Q_{\mathrm{u}} \times f$ of $61000(5.3 \mathrm{GHz})$ and $\tau_{\mathrm{f}}$ of -45 $( \pm 0.6) \mathrm{ppm} /{ }^{\circ} \mathrm{C}$ at the optimized sintering temperature of $700{ }^{\circ} \mathrm{C}$.

The variation of $\epsilon_{\mathrm{r}}$ and $Q_{\mathrm{u}} \times f$ of $\mathrm{MgTe}_{2} \mathrm{O}_{5}$ ceramics at

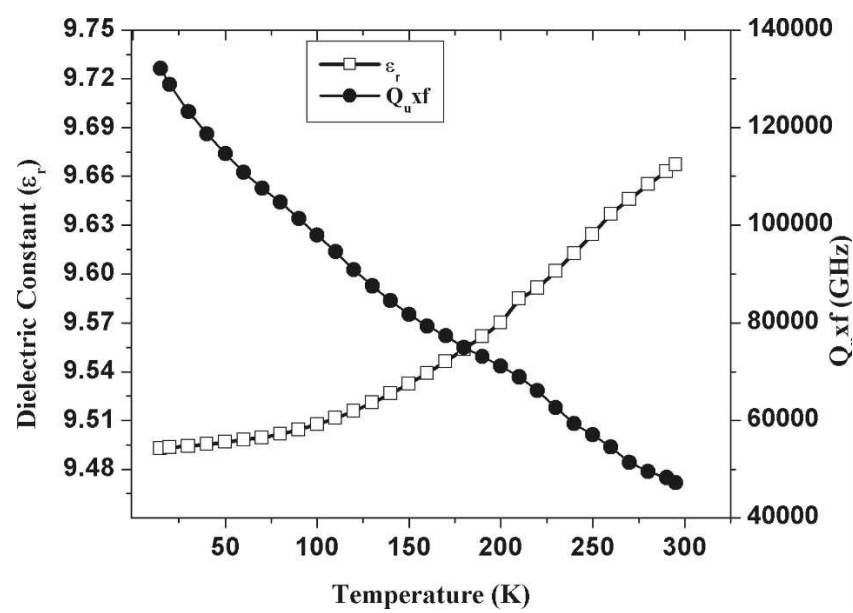

FIG. 7. Variation in dielectric constant and quality factor of $\mathrm{MgTe}_{2} \mathrm{O}_{5}$ ceramics at cryogenic temperatures. cryogenic temperatures is shown in Fig. 7. It can be noted that as the temperature increases from $15 \mathrm{~K}$, the dielectric constant increases slightly, whereas the quality factor decreases. The maximum quality factor of 132,000 and $\epsilon_{\mathrm{r}}$ of 9.49 at $10 \mathrm{GHz}$ were observed at $15 \mathrm{~K}$. A marginal increase of about $1.8 \%$ in $\epsilon_{\mathrm{r}}$ is observed for the $\mathrm{MgTe}_{2} \mathrm{O}_{5}$ ceramics from $15 \mathrm{~K}$ to $290 \mathrm{~K}$. However, the $Q_{\mathrm{u}} \times f$ drops to $48,000 \mathrm{GHz}$ at $290 \mathrm{~K}$. The dielectric loss occurring at microwave frequencies can be due to both intrinsic and extrinsic losses. The intrinsic loss arises because of interactions microwaves with phonons. Thus the decrease in quality factor with temperature can be attributed to the increased interaction of microwaves with phonons. The temperature coefficient of resonant frequency of the $\mathrm{MgTe}_{2} \mathrm{O}_{5}$ ceramics at cryogenic temperatures (from 15 to $100 \mathrm{~K}$ ) is found to be $-277 \mathrm{ppm} /{ }^{\circ} \mathrm{C}$.

\section{CONCLUSIONS}

A single-phase $\mathrm{MgTe}_{2} \mathrm{O}_{5}$ ceramic was obtained with orthorhombic structure after calcining the raw materials at $600{ }^{\circ} \mathrm{C} / 8 \mathrm{~h}$. The single-phase nature of $\mathrm{MgTe}_{2} \mathrm{O}_{5}$ ceramics is confirmed from IR and Raman analyses. However, a very small amount of glassy $\mathrm{MgTe}_{2} \mathrm{O}_{5}$ ceramics is detected in the microstructure. Vibrational analysis shows the existence of $\mathrm{Te}_{2} \mathrm{O}_{5}{ }^{2-}$ groups in $\mathrm{MgTe}_{2} \mathrm{O}_{5}$ with nonlinear Te-O-Te bridging bonds. $\mathrm{MgTe}_{2} \mathrm{O}_{5}$ ceramics has about $6 \%$ percentage shrinkage at the optimized sintering temperature. $\mathrm{MgTe}_{2} \mathrm{O}_{5}$ ceramics have $\epsilon_{\mathrm{r}}=10.5, Q_{\mathrm{u}} \times f=61,000 \mathrm{GHz}$, and $\tau_{\mathrm{f}}=-45 \mathrm{ppm} /{ }^{\circ} \mathrm{C}$ at the optimized sintering temperature of $700{ }^{\circ} \mathrm{C}$. At cryogenic temperatures (at $15 \mathrm{~K}$ ) the material has $\epsilon_{\mathrm{r}}$ of $9.49, Q_{\mathrm{u}} \times f$ of $132,000 \mathrm{GHz}$, and relatively higher $\tau_{\mathrm{f}}$.

\section{ACKNOWLEDGMENT}

G. Subodh is grateful to the Council of Scientific and Industrial Research (CSIR) New Delhi, India, for the award of a junior research fellowship.

\section{REFERENCES}

1. Y. Imanaka: Multilayered Low-Temperature Cofired Ceramic Technology (LTCC), 1st ed. (Springer, New York, 2005), pp. $1-15$.

2. H. Jantunen, R. Rautiaho, A. Uusimaki, and S. Leppavouri: Compositions of $\mathrm{MgTiO}_{3}-\mathrm{CaTiO}_{3}$ ceramics with two borosilicate glasses for LTCC technology. J. Eur. Ceram. Soc. 20, 2331 $\underline{(2000)}$.

3. H. Jantunen, T. Kangasvieri, J. Vahakangas, and S. Leppavouri: Design aspects of microwave components with LTCC technique. J. Eur. Ceram. Soc. 23, 2541 (2003).

4. B.G. Choi, M.G. Stubbs, and C.S. Park: A Ka band narrow band pass filter using LTCC technology. IEEE Micro. Wireless Comp. Lett. 13, 388 (2003).

5. M. Valant and D. Suvorov: Chemical compatibility between silver electrodes and low firing binary oxide compound: Conceptual study. J. Am. Ceram. Soc. 83, 2721 (2000). 
6. H. Jantunen, R. Rautioaho, A. Uusimaki, and S. Leppavuori: Preparing low loss low temperature cofired ceramic material without glass addition. J. Am. Ceram. Soc. 83, 2855 (2000).

7. X. Kuang, G. Larotenuto, and L. Nicolais: A review of ceramic sintering and suggestions on reducing sintering temperature. $\underline{A d v}$. Perform. Mater. 4, 257 (1997)

8. M. Valant and D. Suvorov: Glass free low temperature cofired ceramics: Calcium germinates silicates and tellurates. $\underline{\text { J. Eur. Ce- }}$ ram. Soc. 24, 1715 (2004).

9. J.J. Bian, D.W. Kim, and K.S. Hong: Glass free LTCC microwave dielectric ceramics. Mater. Res. Bull. 40, 2120 (2005).

10. D.K. Kwon, M.T. Lanagan, and T.R. Shrout: Microwave dielectric properties and low temperature firing of $\mathrm{BaTe}_{4} \mathrm{O}_{9}$ with aluminium metal electrode. J. Am. Ceram. Soc. 88, 3419 (2005).

11. G. Subodh and M.T. Sebastian: Glass free $\mathrm{Zn}_{2} \mathrm{Te}_{3} \mathrm{O}_{8}$ microwave ceramic for LTCC applications. J.Am. Ceram. Soc. 90, 2266 (2007).

12. M. Udovic, M. Valant, and D. Suvrov: Dielectric characterization of ceramics from the $\mathrm{TiO}_{2}-\mathrm{TeO}_{2}$ system. J. Eur. Ceram. Soc. 21 1735 (2001).

13. M. Udovic, M. Valant, and D. Suvrov: Phase formation and dielectric characterization of $\mathrm{Bi}_{2} \mathrm{O}_{3}-\mathrm{TeO}_{2}$ system prepared in oxygen atmosphere. J. Am. Ceram. Soc. 87, 591 (2004).

14. K. Kwon, M.T. Lanagan, and T.R. Shrout: Synthesis of $\mathrm{BaTiTe}_{3} \mathrm{O}_{9}$ ceramics for LTCC application and its dielectric properties. J. Ceram. Soc. Jpn. 113, 216 (2005).

15. M.V. Jacob, D. Pamu, and K.C. James Raju: Cryogenic microwave properties of sintered $\left(\mathrm{Zr}_{0.8} \mathrm{Sn}_{0.2}\right) \mathrm{TiO}_{4}$ doped with $\mathrm{CuO}$ and Zno. J.Am. Ceram. Soc. 90, 1511 (2007).
16. B.W. Hakki and P.D. Coleman: A dielectric resonator method of measuring inductive capacitance in the millimeter range. $\underline{I E E E}$ Trans. Microwave Theorv Tech. MTT 8, 402 (1960).

17. J. Krupka, K.D. Derzakowski, B. Riddle, and J.B. Jarvis: A dielectric resonator for measurements of complex permittivity of low loss dielectric materials as a function of temperature. Meas. Sci. Technol. 9, 1751 (1998).

18. M.V. Jacob, J. Mazierska, K. Leong, and J. Krupka: Simplified method for measurements and calculations of coupling coefficients and $\mathrm{Q}_{0}$ factor of high temperature super conducting dielectric resonators. IEEE Trans. Micro. Theory Technol. 49, 2401 (2001).

19. V.M. Tromel: The crystal structure of $\mathrm{MgTe}_{2} \mathrm{O}_{5}$. Z. Anorg. Allg. Chem. 418, 141 (1975).

20. M. Weil: Redetermination of $\mathrm{MgTe}_{2} \mathrm{O}_{5}$. Acta Cryst. E 61, i 237 (2005).

21. E.J. Baran: Vibrational spectrum of the ditellurite ions. $\underline{Z}$. Anorg. Allg. Chem. 442, 112 (1978).

22. I.D. Brown: Bond valence as an aid to understanding the stereochemistry of $\mathrm{O}$ and $\mathrm{F}$ complexs of $\mathrm{Sn}(\mathrm{II}), \mathrm{Sb}$ (III), Te(IV), I(V) and Xe (VI). J. Solid State Chem. 11, 214 (1974).

23. M. Arnaudov, V. Dimitrov, Y. Dimitriev, and L. Markova: Infrared spectral investigation of tellurites. Mater. Res. Bull. 17, 1121 (1982).

24. G. Gospodinov and K. Gyurova: Synthesis, crystallographic data and thermostability of some metal ortho-tellurates of the type $\mathrm{Me}_{3} \mathrm{TeO}_{6}$ and $\mathrm{Me}_{2} \mathrm{TeO}_{6}$. Thermochim. Acta 83, 243 (1985). 